\title{
Poverty, bridging between injecting drug users and the general population, and "interiorization" may explain the spread of HIV in southern Brazil
}

\author{
Mariana A. Hacker ${ }^{a, *}$, Iuri Leite ${ }^{b}$, Samuel R. Friedman ${ }^{c}$, Renata Gracie Carrijo ${ }^{d}$, Francisco I. Bastos ${ }^{d}$ \\ ${ }^{a}$ Leprosy Laboratory, Oswaldo Cruz Institute, Oswaldo Cruz Foundation, Avenida Brasil, 4365, Zip code 21040-360 Rio de Janeiro, Brazil \\ ${ }^{\mathrm{b}}$ National School of Public Health, Oswaldo Cruz Foundation, Avenida Brasil, 4365, Zip code 21040-360 Rio de Janeiro, Brazil \\ ${ }^{\mathrm{c}}$ National Development and Research Institutes, New York, NY 10010, USA \\ ${ }^{\mathrm{d}}$ Institute of Scientific and Technological Information, Oswaldo Cruz Foundation, Avenida Brasil, 4365, Zip code 21040-360 Rio de Janeiro, Brazil
}

\section{A R T I C L E I N F O}

\section{Article history:}

Received 17 December 2007

Received in revised form

1 September 2008

Accepted 8 September 2008

\section{Keywords:}

AIDS

Brazil

Injecting drug users

Poverty

Hierarchical modeling

\begin{abstract}
A B S T R A C T
The aim of this paper is to study how structural determinants and the role of injecting drug users (IDUs) as a bridging population to the general population affected the AIDS subepidemic in southern Brazil during 1986-2000. Data from 288 southernmost Brazilian municipalities were analyzed. Using hierarchical modeling and inputs from a Geographic Information System, a multilevel model was constructed. The dependent variable was the logged AIDS standardized incidence rate (among the heterosexual population aged 15-69-years-old); independent variables included indicators for education, water provision, sewage, and garbage collection, per capita income, Gini coefficient (on income), Human Development Index, indicators of accessibility, and AIDS rate among IDUs. Significant predictors included AIDS rate among IDUs, distance from/to highways/railways, the Human Development Index and the ratio of residents who have access to sanitary installations. Poverty (as measured by socioeconomic indicators) and bridging from IDUs contribute to the spread of HIV/AIDS in Brazilian southern municipalities.
\end{abstract}

(c) 2008 Elsevier Ltd. All rights reserved.

\section{Introduction}

The AIDS epidemic in Brazil commenced in the early 1980s and since then has passed through many different phases and regional patterns (Petersen et al., 2006; Hacker et al., 2006). AIDS incidence declined in the period 2001-2004 and remained stable thereafter, with 17.2 AIDS cases per 1,00,000 since 2004 (Brazilian Ministry of Health (BMoH), 2005, 2006).

Initially, gay and bisexual men, mainly from higher and middle social ranks, were deeply affected, as well as recipients of blood and blood derivatives (Lowndes et al., 2000; Petersen et al., 2006). AIDS cases among injecting drug users (IDUs) were registered at a fast pace in the late 1980s/early 1990s, with a substantial decline after the mid-1990s $(\mathrm{BMoH}, 2005$; Hacker et al., 2006).

In the first years of the present decade (2000-2006), the subepidemics in the two most populous and industrialized Brazilian regions-the southeastern and southern regionsfollowed contrasting patterns. Whereas the epidemic has been consistently declining in the southeast, it progressed unabated in the south up to 2006, both among IDUs and among non-IDU

\footnotetext{
* Corresponding author. Tel.: 552125984 287; fax: 552122709997

E-mail address: marianah@ioc.fiocruz.br (M.A. Hacker).
}

people who acquired the infection through unprotected heterosexual intercourse, without an IDU history up to 2006.

Much has been debated worldwide on the role of IDUs as a bridging population, contributing to the spread of HIV and other sexually transmitted infections and blood-borne pathogens to the so-called general population (Williams et al., 2003; Qian et al., 2005).

The inconsistent use of condoms among IDUs and their sexual partners has been reported in different contexts (Friedman et al., 1994; Sherman and Latkin, 2001; Hacker et al., 2005; Pechansky, et al., 2005). Recent papers have highlighted the often disregarded central role of sexual risk behaviors in the transmission of HIV among IDUs (Flom et al., 2001; Strathdee and Sherman, 2003; Hacker et al., 2005; Neaigus et al., 2001) and between them and their non-injecting sexual partners (Williams et al., 2005).

A recent paper assessed the association of socioeconomic and structural indicators and AIDS incidence among IDUs from different Brazilian regions (Hacker et al., 2006). This paper made evident the deep heterogeneity of the Brazilian AIDS subepidemics in the IDU population. The epidemic in this specific population was sizeable, but has been declining in the southeastern region. On the other hand, the role of IDUs in the northern and northeastern subepidemics has been negligible, whereas it was substantial in the southernmost states, Santa Catarina and Rio Grande do Sul (BMoH, 2005; Hacker et al., 2006) until very 
recently, when IDU has been replaced by crack smoking in Brazil's southernmost states (Inciardi et al., 2006).

The present paper focuses on the Brazilian southern subepidemic dynamic, taking into consideration both its structural determinants as well as the role IDUs may have as a bridging population to the general population.

\section{Methods}

Our basic dataset was composed by AIDS cases due to heterosexual transmission ${ }^{1}$ registered among the population aged 15-69-years-old, living in the 288 southernmost municipalities, i.e. living in the southern states of Paraná (PR), Santa Catarina (SC), and Rio Grande do Sul (RS). These data were downloaded from SINAN-AIDS (National AIDS Notification System) for the 15-yearperiod 1986-2000.

The earliest years of the epidemic were excluded from analysis in order to avoid unstable rates due to small numbers of cases. The period under analysis corresponds to the years when the southern epidemic commenced and took momentum, and before transition toward non-injectable use of cocaine took place in Brazil's southernmost states.

In order to standardize the effect of the age and sex structures of the different municipal populations, we calculated the directly standardized AIDS rate by age groups (15-19, 20-29, 30-39, $40-49,50-59$, and 60-69) and sex, using the Brazilian population for the year 2000 (national census) as a reference.

A set of socioeconomic and structural indicators which could be associated with the variability of the standardized rates of AIDS cases among heterosexuals (outcome variable) was constructed for each municipality (roughly equivalent to "counties" in the North American nomenclature, i.e. comprising the town/village that gives the name to each Brazilian municipality and its surroundings, either urban, semi-urban or rural), using 1991 and 2000 census data. Independent variables thus included: adult literacy rate; proportion of residents with (a) full water provision; (b) municipal garbage collection service, and (c) access to sewage systems (as indicators for housing standards); per capita income and the Gini coefficient were used to assess the income and income inequality. In relation to social vulnerability and health infra-structure, we used two indicators: the proportion of households headed by women with children younger than 15 -years-old; and the number of physicians per inhabitant. We used the Human Development Index (HDI) as a composite index that measures average achievement in three basic aspects of human development: longevity, literacy, and standard of living (available at www.undp.org). To describe population dispersion we used the proportion of urban population for each municipality. Proportion of persons older than 15 years old who completed 8 years of education was also available from a comprehensive inter-census assessment of educational indicators carried out in 1996.

Besides intra-municipal indicators, we defined indicators of accessibility, using information from digital maps and compilations made available by National Department of Transportation Infrastructure. We assessed whether each municipality's main town/village was more than $5000 \mathrm{~m}$ distant from the main (federal) highways/railways and served/not served by an airport. These variables were entered into the models as three dummy variables, with 0 as the reference category and 1 for the presence of each one of the independent connections (highway $<5000 \mathrm{~m}$;

\footnotetext{
1 i.e. those defined as belonging to exposure category "heterosexual transmission" corresponding to SINAN-AIDS-National AIDS Notification System-codes 30- Heterosexual and 36- Heterosexual with undefined risk partnership.
}

railway $<5000 \mathrm{~m}$, airport connection available in the municipal area). The indicators of accessibility were built using information from different layers (geographic boundaries of municipalities and respective geographic centers, highways, railways and airports) from the FIOCRUZ GIS (Geographic Information System) (broadly adopting criteria defined by Vine et al., 1997).

Indicators for education, water provision, sewage, and garbage collection were downloaded from the DATASUS (Brazil Unified Health System Databank) home-page, at http://www.datasus.gov.br). All the other indicators were downloaded from the Brazilian site of the United Nations Development Programme (PNUD-Brasil) (http://www.pnud.org.br).

AIDS cases among IDUs were defined using the UNAIDS hierarchical classification, comprising both single and composed categories defined by the SINAN-AIDS. In this approach, injection drug users are classified under this broad category, even if included in additional exposure categories. ${ }^{2}$ In sum, both variables that could be defined as meso-level variables (e.g. unprotected sex between IDUs and their partners who do not inject illicit drugs) and macro-level (e.g. sanitary conditions of different communities) were assessed by the analyses carried out.

The AIDS cases rates among IDUs, the covariate of interest, were dichotomized taking the median rate $(0.108$ cases per 1000 inhabitants) as a cut-point. The reference category was defined by the values below the median. Exploratory analyses attempted to model this covariate as a continuous variable, but it was not possible to fit the model this way, due to the asymmetric distribution of this covariate.

In order to assess collinearity between indicators, correlation coefficients were calculated for the main putative collinearities, (for instance, the HDI as a composite index included literacy as one of its components, with an obvious overlapping with adult literacy rate).

Because the data structure allows for multiple observations (over the years) of single units of analysis (municipalities), a hierarchical multilevel model was used, with years being the first level and municipalities the second level.

Multilevel analysis is a method that can be applied for the analysis of data with nested source of variability such as longitudinal measurements (e.g., rates of specific disease from several localities measured for several years). In analyzing this kind of data, it is necessary to take account of the variability associated with each level of nesting. (Snijders and Bosker, 1999).

A first simple model was fitted using time as the single covariate to explore the best form to adjust the effect of time on AIDS rate. As we have only three states, they were not included as a higher level in the geographical hierarchy, but rather as dummy variables, with Santa Catarina (the state with the greatest number of municipalities with increasing incidence AIDS rates- $\mathrm{BMoH}$, 2005) as the reference category.

A two-level multilevel linear model (time nested into municipalities) was fitted through the statistical software MLwiN, version 2.0 (Rasbash et al., 2000). In this model, we included time as a random coefficient, allowing its effect to be different depending on the municipality.

\footnotetext{
${ }^{2}$ We used the categories as follows with their respective codes: 11Homosexual/Drug use, 14-Homosexual/Drug use/Hemophilic, 15-Homosexual/ Drug use/Blood Transfusion, 21-Bisexual/Drug use, 24-Bisexual/Drug use/Hemophilic, 25-Bisexual/Droga use/Blood Transfusion, 31-Heterosexual/Drug use, 34Heterosexual/Drug use/Hemophilic, 35-Heterosexual/Drug use/Blood Transfusion, 40-Drug Use, 41-Drug use/Hemophilic, 42-Drug use/Blood Transfusion, 61-Blood Transfusion/Drug use, 64-Blood Transfusion/Drug Use/Homosexual, 65-Blood Transfusion/Drug Use/ Bisexual \& 67-Blood Transfusion/Drug Use/Heterosexual, as defined by SINAN-AIDS, Brazilian Ministry of Health.
} 
Firstly, bivariate associations were assessed and the variables statistically significant at $5 \%$ were selected for the multivariate analysis. Second-order interaction terms were added and tested. Variables with a significance level of $5 \%$ were maintained in the model.

The results are presented as both thematic maps and a table summarizing the main findings of the multilevel model.

\section{Results}

In the bivariate analyses the following variables were shown to be associated with the logged AIDS standardized incidence rate

Table 1

Coefficient and standard error (SE) of the variables of the final multilevel model.

\begin{tabular}{lcc}
\hline Variables & Coefficient (SE) & $p$-Values \\
\hline $\begin{array}{l}\text { Fixed part } \\
\text { Constant }\end{array}$ & $-2.711(1.072)$ & 0.011 \\
$\begin{array}{l}\text { First level terms } \\
\text { Time }\end{array}$ & $0.030(0.008)$ & $<0.001$ \\
Second level terms & & \\
AIDS rate among IDUs & & $<0.001$ \\
Above median value & $0.184(0.043)$ & $<0.001$ \\
HDI & $-5.446(1.331)$ & $<0.001$ \\
Sanitary installations & $-0.011(0.003)$ & $<0.001$ \\
$\begin{array}{l}\text { Dummy variables } \\
\text { Highways }<5000 \mathrm{~m}\end{array}$ & & 0.014 \\
Railways $<5000 \mathrm{~m}$ & $-0.479(0.099)$ & \\
State & $-0.216(0.088)$ & $<0.001$ \\
(Santa Catarina $=$ reference) & & \\
$\quad$ Rio Grande do Sul & & \\
Paraná & & $<0.001$ \\
& $-0.168(0.106)$ & \\
Random part & $-0.288(0.133)$ & \\
Constant & & \\
Time & & \\
\hline
\end{tabular}

(among heterosexuals): AIDS rate among IDUs, HDI, proportion of residents who have access to sanitary installations, proportion of households headed by women with children younger than 15 years old, and proportion of urban population.

In the final multivariate model (Table 1 ), the following variables were associated with the logged AIDS standardized incidence rate (among heterosexuals): AIDS rate among IDUs, two indicators of accessibility (distance from/to highways/railways), HDI and proportion of residents who have access to sanitary installations. The two latter indicators are referred to year 2000 (Census data) and were found to be inversely associated with the outcome, i.e. the greater the proportion of residents with access to sanitary installations (from $0.04 \%$ to $79 \%$ ) and the higher the HDI, the lower the AIDS incidence among heterosexuals in a given municipality.

Two indicators of accessibility (distance from/to highways/ railways) were found to be inversely associated with the outcome, i.e. those municipalities located far away from the main routes connecting the network of smaller municipalities with metropolitan centers have been affected by higher AIDS incidence rates$83 \%$ of these municipalities are located near (less than $5000 \mathrm{~m}$ ) highways and $48 \%$ are near to railways. Presence/absence of airports was not associated with outcome. Residual analyses were carried out to evaluate the underlying assumptions of the multilevel model. Assumption of normality of residuals was verified.

The AIDS rate among IDUs was found to be positively and significantly associated with the logged AIDS standardized incidence rate among heterosexuals, after controlling for different social and structural indicators.

The analysis of the dummy covariate related to the three southern states (Paraná-PR, Santa Catarina_SC and Rio Grande do Sul-RS) highlighted a smaller logged AIDS standardized incidence rate among heterosexuals in Rio Grande do Sul and Paraná vis-à-vis Santa Catarina.

The visual inspection of the thematic maps helps to understand the model's findings in context. Fig. 1 illustrates HDI indexes
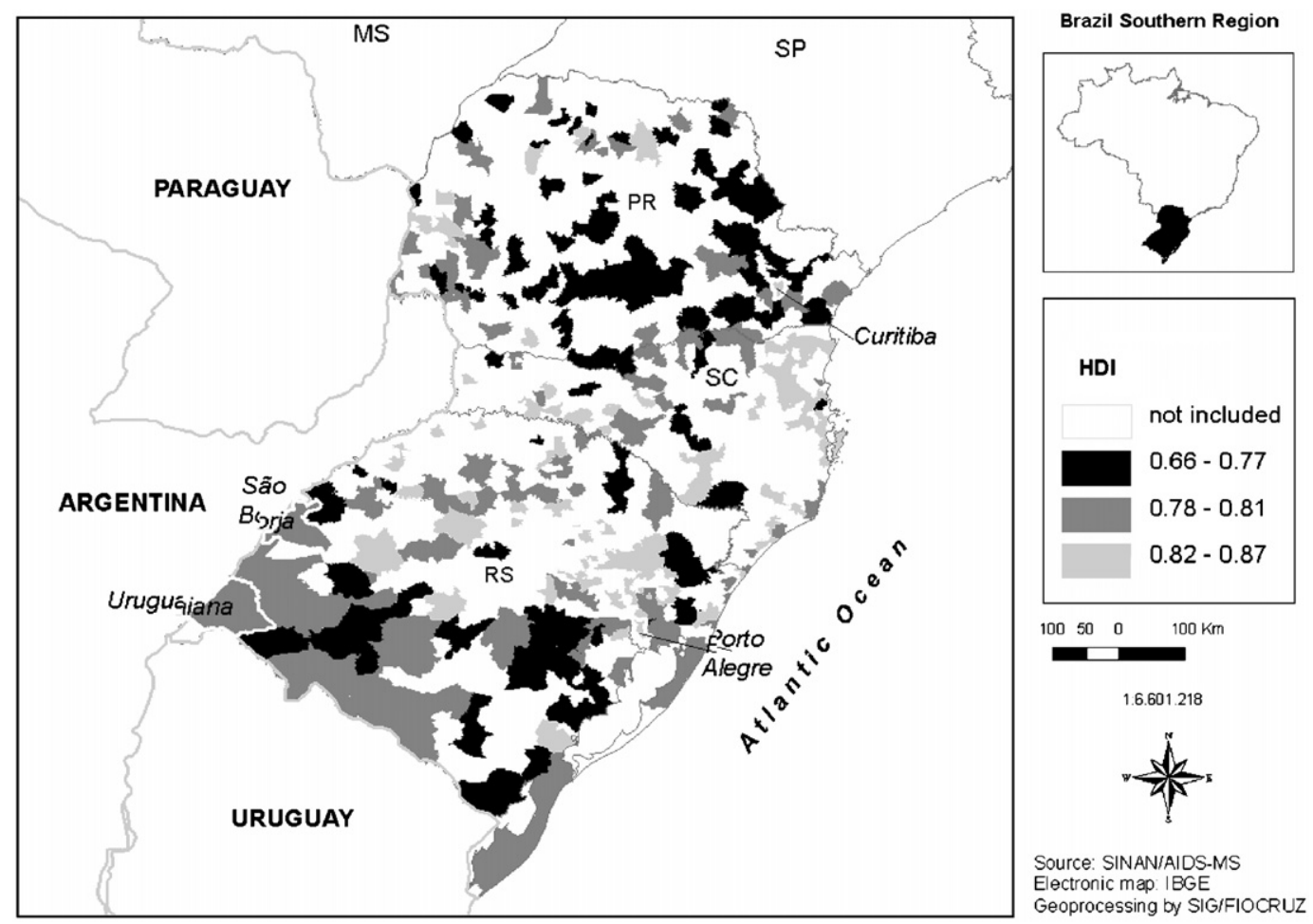

Fig. 1. HDI of selected municipalities, south region, Brazil, 2000. 

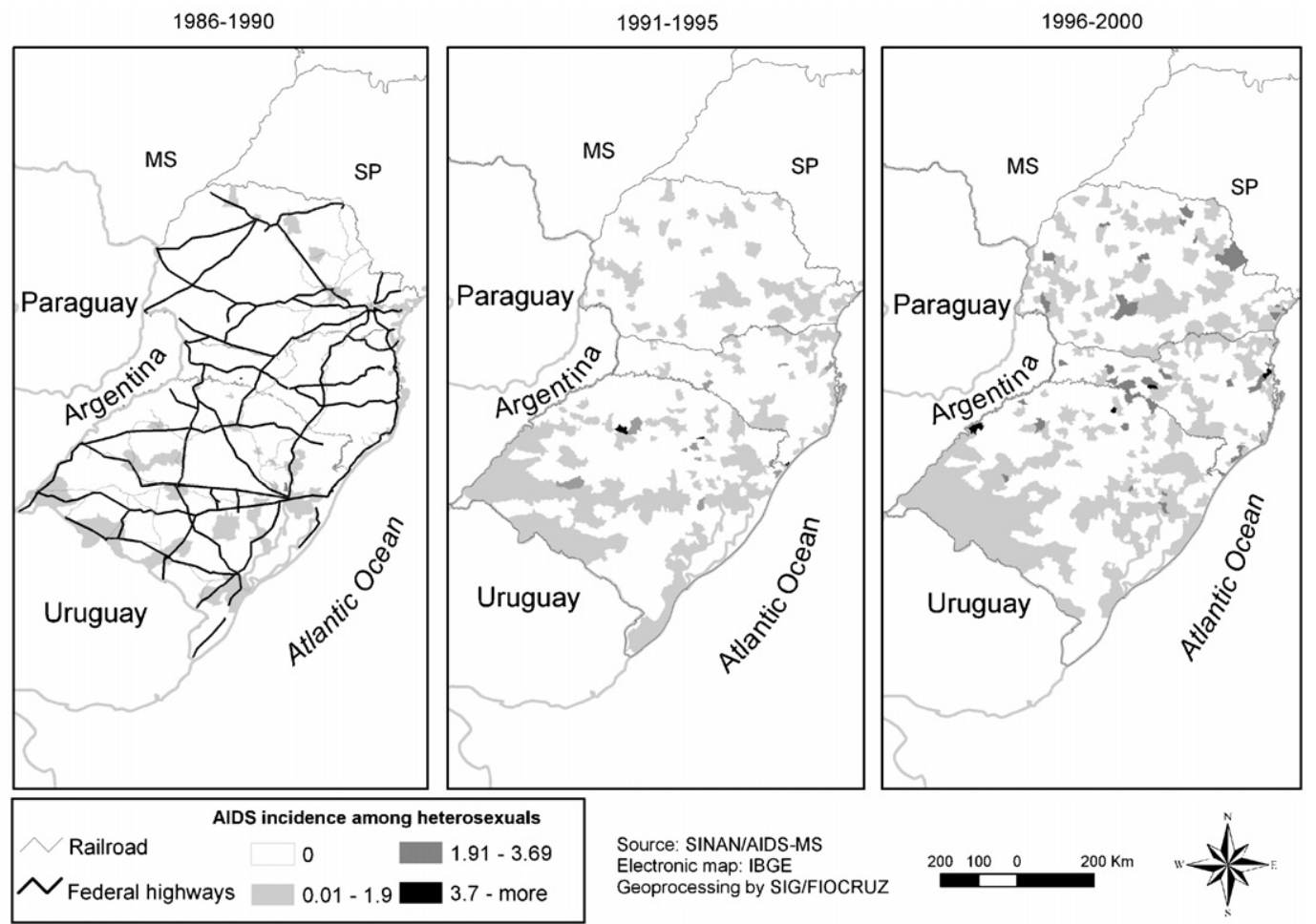

Fig. 2. Accumulated AIDS incidence rate (per 1000 inhabitants) among IDUs in south region, Brazil, 1986-2000.
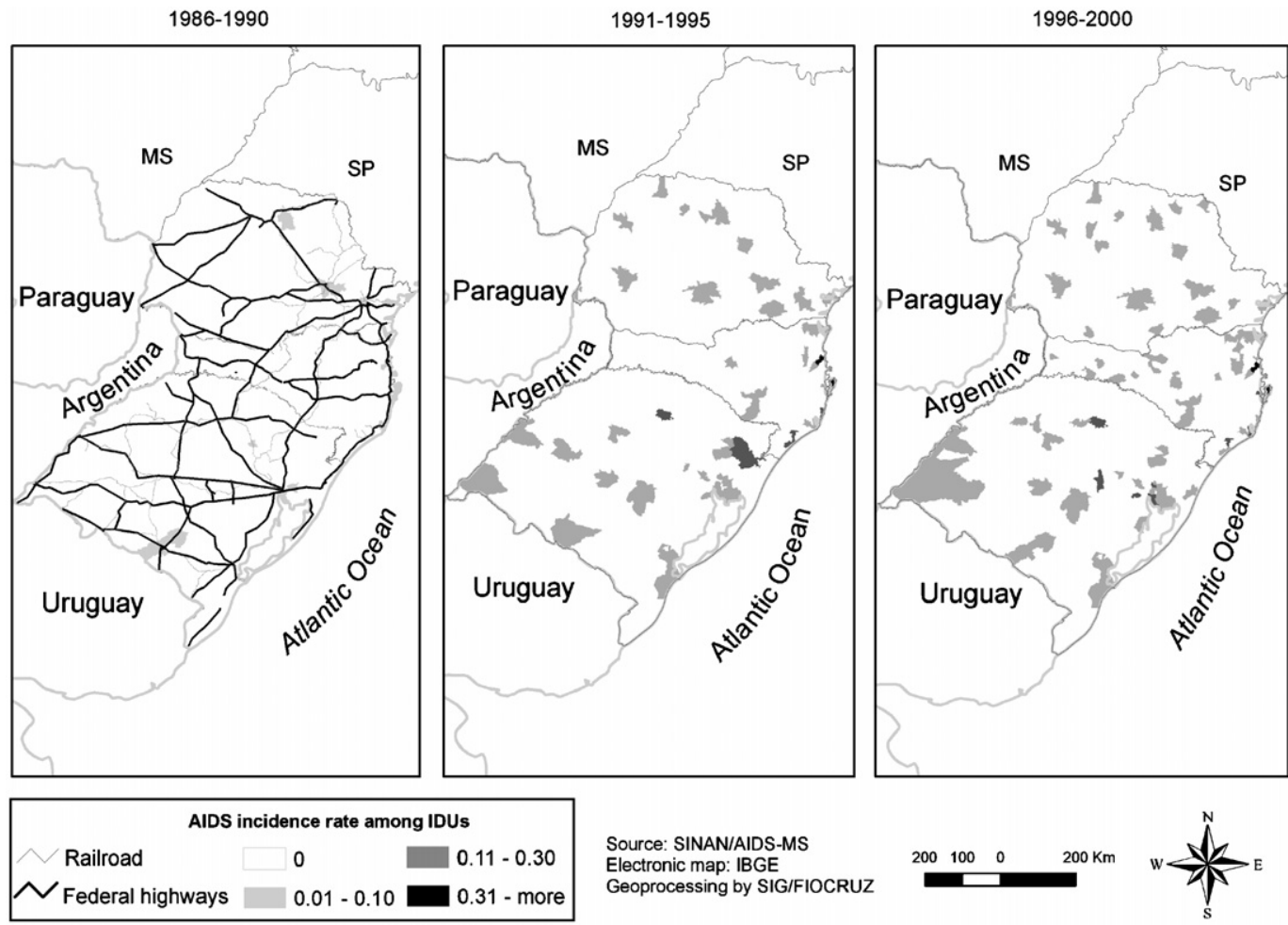

Fig. 3. Accumulated AIDS incidence rate (per 1000 inhabitants) among heterosexuals, south region, Brazil, 1986-2000.

for the southern municipalities under analysis. Although HDI indexes for the southern region are relatively high vis-à-vis overall Brazilian indexes (data not shown), there is a relevant variation between such indexes. There is a spatial overlapping between municipalities with lower HDIs and areas where the epidemic among both heterosexuals and IDUs has been spreading in the period under observation. (Figs. 1-3).

Fig. 2 depicts the accumulated AIDS incidence among IDUs, per 1000 inhabitants for each municipality. High accumulated rates can be found in municipalities located close to international 
borders (with Argentina and Uruguay), such as Uruguaiana (RS) and São Borja (RS).

Fig. 3 illustrates accumulated AIDS incidence rates among heterosexuals (men and women, in three periods: 1986-1990, 1991-1995, and 1996-2000), per 1000 inhabitants for each municipality.

AIDS cases among heterosexuals present a more diffuse geographic pattern compared to cases registered among IDUs, with an additional concentration in the metropolitan areas around the capitals of the states of Rio Grande do Sul (Porto Alegre) and Paraná (Curitiba). AIDS cases among heterosexuals cluster as well around the main highways, as depicted in Fig. 2. However, when the standardized rate is modeled over time, AIDS rates increase in recent years in those municipalities located far way from the main highways and railways.

\section{Discussion}

Both HDI and the proportion of residents who have access to sanitary installations were found to be inversely associated with AIDS rates. These findings may reflect the "impoverishment" of the epidemic in Brazil, i.e. the progressive spread of the epidemic toward impoverished communities (Szwarcwald et al., 2001), as expressed by the proportional increase of AIDS cases among people with a lower educational background (Fonseca et al., 2002) and unemployed and/or working in low-paid occupations (Fonseca et al., 2003).

This process of impoverishment seems to be especially relevant in the Brazilian south, a region originally inhabited by European migrants (especially Germans and Italians), that nowadays compose a vast (for Brazilian standards) affluent middle-class, amidst a growing population of impoverished agricultural workers and low-paid/unemployed urban dwellers. Former studies carried out at the individual level documented the high infection rates of both HIV and Human T cell lymphotropic viruses type 1 and 2 (Morimoto et al., 2005) among impoverished social strata in municipalities from the state of Paraná.

The geoprocessing of data let us to triangulate the findings from the model, putting them in the context of Brazilian geography and demographics. There is a clear overlapping between areas where the epidemic has been affecting IDUs and heterosexuals, and between such areas and the municipalities which score poorly on the human development index.

The inverse association between the standardized AIDS rate and municipalities with better accessibility seems to reflect the trend of the Brazilian epidemic to spread over time not only toward impoverished communities, but also toward middle-sized and smaller municipalities located far away from the main metropolitan areas over time (Petersen et al., 2006). The combined effects of these two overarching tendencies make the middle-sized and small municipalities with lower human development standards and worse infra-structure particularly vulnerable.

A vast literature (Victora et al., 1992; Cesar et al., 1997; Victora and Vaughan, 1997; Lima et al., 1999; Barros et al., 2001) documents the somber effects of poverty and social inequality in southern Brazil on a variety of medical conditions and social problems. The different studies carried out in southern Brazil highlight a combined adverse effect of absolute deprivation (in some specific areas and populations) and social inequality on health standards, as discussed in the international literature (Marmot, 2003).

Socioeconomic determinants, individual behaviors and small network interaction patterns have been explored as predictors of HIV/AIDS by the international literature. Broad social and economic determinants of AIDS spread have been explored by recent publications (Boerma and Weir, 2005; Rhodes et al., 2005; Friedman et al., 2006; Stillwaggon, 2005).

The interplay of determinants at the level of individuals, their networks and the society at large is especially relevant among IDUs, due to the complex inter-relationship of individual behaviors and communities in the frame of a powerful illicit market, ruled by contradictory policies emphasizing either the enforcement of the law or public health, and plagued by structural violence (Friedman et al., 1999; Galea et al., 2003; Rhodes et al., 2005; Friedman et al., 2006).

Most IDUs do not fit to the stereotype of isolated individuals living in secluded places, but indeed interact with non-injecting sexual partners and with their respective communities. Due to their special vulnerability to blood-borne infections they may function as a bridge to the general population for HIV and other sexually and blood-borne pathogens such as hepatitis B (Friedman et al., 1994; Friedman et al., 2003; Williams et al., 2003; Williams et al., 2005; Friedman et al., 2007).

In a former study carried out in a network of southern centers for HIV testing and counseling, partnership with IDUs was found to be a key risk factor for HIV infection among non-injecting heterosexuals (Barcellos et al., 2003).

In sum, the present study, profiting from hierarchical multilevel modeling and GIS, documents the combined role of poverty and bridging from injection drug users on the unabated spread of HIV/AIDS in Brazilian southern municipalities.

Ecological studies, on one hand, are essential to catch the broad picture, never assessed before in the Brazilian south. On the other hand, they miss details that can be studied by individuallevel studies. Besides the usual limitations found in the analysis of secondary data, the present study did not explore the potential impact of HIV diversity. A recent study by Salemi et al. (2005) hypothesizes HIV subtypes B and C have different epidemic potentials, which may explain why the southern Brazilian southern subepidemic, driven by HIV $C$ subtype, has been spreading unabated whereas the southeastern subepidemic, driven by $\mathrm{B}$ subtype infections, has been on decline.

Our study refines previous analyses documenting the pivotal role of IDUs in the southern Brazil subepidemic. The present study extends former conclusions, exploring the putative bridging from IDUs toward the general population, at the ecological level, and highlighted two additional dimensions - the role of poverty as a main contributor to the observed dynamic and the flow between municipalities.

Public policies must be tailored to regional and social specificities. The full integration of studies carried out at the level of individuals, communities and broad geographic areas is pivotal in a multifarious and complex epidemic such as the ongoing HIV/AIDS epidemic, especially in a country with vast dimensions and striking social contrasts such as Brazil. The present study brought new insights to the challenge posed by the vigorous spread of HIV/AIDS in southern Brazil, a region where the undeniable achievements of the Brazilian AIDS Program as a whole did not reach the same favorable results everywhere.

\section{References}

Barcellos, N.T., Fuchs, S.C., Fuchs, F.D., 2003. Prevalence of and risk factors for HIV infection in individuals testing for HIV at counseling centers in Brazil. Sexually Transmitted Disease 30 (2), 166-173.

Barros, F.C., Victora, C.G., Horta, B.L., 2001. Ethnicity and infant health in Southern Brazil. A birth cohort study. International Journal of Epidemiology 30 (5), 1001-1008.

Boerma, J.T., Weir, S.S., 2005. Integrating demographic and epidemiological approaches to research on HIV/AIDS: the proximate-determinants framework. The Journal of Infectious Diseases 191 (Suppl. 1), S61-S67. 
Brazilian Ministry of Health/Ministério da Saúde, 2005. Boletim Epidemiológico Janeiro a Junho de 2005. Ano II no. 01-1 a $26^{\mathrm{a}}$ semanas epidemiológicas-ISSN 1517 1159. Em 〈www.aids.gov.br〉. (Accessed on 12/08/2005).

Brazilian Ministry of Health/Ministério da Saúde, 2006. Boletim Epidemiológico Janeiro a Junho de 2006. Ano III no. 01- $1^{\text {a }}$ a $26^{\text {a }}$ semanas epidemiológicas-ISSN 1517 1159. Em 〈www.aids.gov.br〉. (Accessed on 03/20/2006).

Cesar, J.A., Victora, C.G., Santos, I.S., Barros, F.C., Albernaz, E.P., Oliveira, L.M., Flores, J.A., Horta, B.L., Weiderpass, E., Halpern, R., 1997. Hospitalization due to pneumonia: the influence of socioeconomic and pregnancy factors in a cohort of children in Southern Brazil. Revista de Saude Publica 31 (1), 53-61.

Flom, P.L., Friedman, S.R., Kottiri, B.J., Neaigus, A., Curtis, R., Des Jarlais, D.C., Sandoval, M., Zenilman, J.M., 2001. Stigmatized drug use, sexual partner concurrency, and other sex risk network and behavior characteristics of 18- to 24-year-old youth in a high-risk neighborhood. Sexually Transmitted Disease 28 (10), 598-607.

Fonseca, M.G., Szwarcwald, C.L., Bastos, F.I., 2002. A sociodemographic analysis of the AIDS epidemic in Brazil, 1989-1997. Revista de Saude Publica 36 (6) 678-685.

Fonseca, M.G., Travassos, C., Bastos, F.I., Silva Ndo, V., Szwarcwald, C.L., 2003. Social distribution of AIDS in Brazil, according to labor market participation, occupation and socioeconomic status of cases from 1987 to 1998. Cadernos de Saude Publica 19 (5), 1351-1363.

Friedman, S.R., Jose, B., Neaigus, A., Goldstein, M., Curtis, R., Ildefonso, G., Mota, P., Des Jarlais, D.C., 1994. Consistent condom use in relationships between seropositive injecting drug users and sex partners who do not inject drugs. AIDS 8, 357-361.

Friedman, S.R., Curtis, R., Neaigus, A., Jose, B., Des Jarlais, D.C., 1999. Social Networks, Drug Injectors' Lives, and HIV/AIDS. Kluwer/Plenum, New York.

Friedman, S.R., Flom, P.L., Kottiri, B.J., Zenilman, J.M., Curtis, R., Neaigus, A., Sandoval, M., Quinn, T., Des Jarlais, D.C., 2003. Drug use patterns and infection with sexually transmissible agents among young adults in a high-risk neighborhood in New York City. Addiction 98, 159-169.

Friedman, S.R., Cooper, H.L., Tempalski, B., Keem, M., Friedman, R., Flom, P.L., Des Jarlais, D.C., 2006. Relationships of deterrence and law enforcement to drugrelated harms among drug injectors in US metropolitan areas. AIDS 20 (1) 93-99.

Friedman, S.R., Bolyard, M., Mateu-Gelabert, P., Goltzman, P., Pawlowicz, M.P., Zunino Singh, D., Touze, G., Rossi, D., Maslow, C, Sandoval, M., Flom, P.L, 2007. Some data-driven reflections on priorities in AIDS network research. AIDS and Behavior 11 (5), 641-651.

Galea, S., Ahern, J., Vlahov, D., 2003. Contextual determinants of drug use risk behavior: a theoretic framework. Journal of Urban Health 80 (4), iii50-iii58.

Hacker, M.A., Friedman, S.R., Telles, P.R., Teixeira, S.L., Bongertz, V., Morgado, M.G., Bastos, F.I., 2005. The role of "long-term" and "new injectors" in a declining HIV/AIDS epidemic in Rio de Janeiro, Brazil. Substance Use and Misuse 40 (1) 99-123.

Hacker, M.A., Leite, I.C., Renton, A., Guillen, T.T., Gracie, R., Bastos, F.I., 2006 Reconstructing the AIDS epidemic among Brazilian injection drug users. Cadernos de Saude Publica 22 (4), 751-760.

Inciardi, J.A., Surratt, H.L., Pechansky, F., Kessler, F., von Diemen, L., da Silva, E.M. Martin, S.S., 2006. Changing patterns of cocaine use and HIV risks in the south of Brazil. Journal of Psychoactive Drugs 38 (3), 305-310.

Lima, R.C., Victora, C.G., Dall'Agnol, M., Fassa, A., 1999. Association between individual and socioeconomic characteristics and work-related accidents in Pelotas, Southern Brazil. Cadernos de Saude Publica 15 (3), 569-580.

Lowndes, C.M., Bastos, F.I., Giffin, K.M., Vaz dos Reis, A.C., d'Orsi, E., Alary, M., 2000. Differential trends in mortality from AIDS in men and women in Brazil (1984-1995). AIDS 14 (9), 1269-1273.
Marmot, M.G., 2003. Understanding social inequalities in health. Perspectives in Biology and Medicine 46 (Suppl. 3), S9-23.

Morimoto, H.K., Caterino-De-Araujo, A., Morimoto, A.A., Reiche, E.M., Ueda, L.T. Matsuo, T., Stegmann, J.W., Reiche, F.V., 2005. Seroprevalence and risk factors for human $\mathrm{T}$ cell lymphotropic virus type 1 and 2 infection in human immunodeficiency virus-infected patients attending AIDS referral center health units in Londrina and other communities in Parana, Brazil. AIDS Research and Human Retroviruses 21 (4), 256-262.

Neaigus, A., Miller, M., Friedman, S.R., Des Jarlais, D.C., 2001. Sexual transmission risk among noninjecting heroin users infected with human immunodeficiency virus or hepatitis C virus. Journal of Infectious Diseases 184 (3), 359-363.

Pechansky, F., Kessler, F., Von Diemen, L., Inciardi, J.A., Surratt, H., 2005. Substance use, risk situations, and HIV seroprevalence among individuals seeking free HIV testing in Porto Alegre, Brazil. Revista Panamericana de Salud Publica 18 (4), 249-255.

Petersen, M., Travassos, C., Bastos, F.I., Hacker, M.A., Beck, E., Noronha, J., 2006. Brazil. In: Beck, E.J., et al. (Eds.), The HIV Pandemic: Local and Global Implications. Oxford University Press, Oxford, pp. 429-446.

Qian, Z.H., Vermund, S.H., Wang, N., 2005. Risk of HIV/AIDS in China: subpopulations of special importance. Sexually Transmitted Infections 81 (6), 442-447.

Rasbash, J., Browne, W., Goldstein, H., Yang, M., Plewis, I., Healy, M., Woodhouse, G., Draper, D., Langford, I., Lewis, T., 2000. A User's Guide to MLwiN, second ed. Institute of Education, London.

Rhodes, T., Singer, M., Bourgois, P., Friedman, S.R., Strathdee, S.A., 2005. The social structural production of HIV risk among injecting drug users. Social Science and Medicine 61 (5), 1026-1044.

Salemi, M., de Oliveira, T., Soares, M.A., Pybus, O., Dumans, A.T., Vandamme, A.M., Tanuri, A., Cassol, S., Fitch, W.M., 2005. Different epidemic potentials of the HIV-1B and C subtypes. Journal of Molecular Evolution 60 (5), 598-605.

Sherman, S.G., Latkin, C.A., 2001. Intimate relationship characteristics associated with condom use among drug users and their sex partners: a multilevel analysis. Drug and Alcohol Dependence 64 (1), 97-104.

Snijders, T.A.B., Bosker, R.J., 1999. Multilevel Analysis: An Introduction to Basic and Advanced Multilevel Modeling. SAGE Publications, London.

Stillwaggon, E., 2005. AIDS and the Ecology of Poverty. Oxford University Press, New York

Strathdee, S.A., Sherman, S.G., 2003. The role of sexual transmission of HIV infection among injection and non-injection drug users. Journal of Urban Health 80 (4 Suppl. 3), iii7-14.

Szwarcwald, C.L., Bastos, F.I., Barcellos, C., Esteves, M.A., Castilho, E.A., 2001. AIDS epidemic dynamics in the municipality of Rio de Janeiro, Brazil, 1988-1996: spatial-temporal statistic modeling. Cadernos de Saude Publica 17 (5), 1123-1140.

Victora, C.G., Vaughan, J.P., 1997. Land tenure and child health in Rio Grande do Sul: the relationship between agricultural production, malnutrition and mortality. Brazilian Journal of Population Studies 1, 123-143.

Victora, C.G., Barros, F.C., Huttly, S.R., Teixeira, A.M., Vaughan, J.P., 1992. Early childhood mortality in a Brazilian cohort: the roles of birthweight and socioeconomic status. International Journal of Epidemiology 21 (5), 911-915.

Vine, M.F., Degnan, D.E., Hanchette, C., 1997. Geographic Information Systems: their use in environmental epidemiologic Research. Environmental Health Perspectives 105 (6), 598-605.

Williams, M.L., Bowen, A.M., Timpson, S., Blair Keel, K., 2003. Drug injection and sexual mixing patterns of drug-using male sex workers. Sexually Transmitted Disease 30 (7), 571-574.

Williams, M.L., Atkinson, J., Klovdahl, A., Ross, M.W., Timpson, S., 2005. Spatial bridging in a network of drug-using male sex workers. Journal of Urban Health 82 (1 Suppl 1), i35-42. 